\title{
Children's Embodied Voices: Approaching Children's Experiences Through Multi-Modal Interviewing
}

\author{
Dr. Charlotte Svendler Nielsen, Department of Exercise and Sport Sciences, University of \\ Copenhagen, Denmark \\ Email: csnielsen@ifi.ku.dk
}

\section{Abstract}

This article focuses on a multi-modal interview approach that has been developed as part of a research project. The goal of the research was to explore and better understand children's embodied experiences and expressions in movement. The multi-modal interview approach emphasizes the non-verbal, giving children an opportunity to focus on "the felt sense" (Gendlin, 1983), and to express their experiences in a variety of forms and through the use of metaphors (Egan, 1997; Gendlin, 1983, 1997). Inspired by Arnold Mindell's (1985) work on shifting channels in our ways of experiencing the world, this paper works with an adaptation of Eugene T. Gendlin's “focusing technique”-one that significantly expands Gendlin's repertoire of modalities by using drawing, colours, words, sound, music and movement. Narratives have been created using children's voices and expressions. The article includes an example of a narrative that illustrates how the approach has helped children express their movement experiences. The narrative is analysed by means of a hermeneutic phenomenological approach (van Manen, 1990), through which themes/lived meanings of the child's experiences are elucidated. The article closes with a discussion of how the multi-modal interview approach can help to cast light on the relationships between body, movement, and language, and how the approach could also inspire a somatic perspective when teaching movement and dance in schools.

\section{Introduction}

We constantly experience and express ourselves through our bodies, and children use their bodies to communicate even before they develop a verbal language. The body is central in our efforts to create meaning and make sense of our experiences. For example, when children develop concepts of wet and dry, wet means wetter than my body (Egan, 1997, p. 40). It is through our bodies that we translate our perceptions to actions and vice versa-actions also colour our perceptions. According to Kieran Egan (1997), curriculum should involve the somatic ${ }^{1}$ dimension to a much higher degree and ensure that this dimension is a continuous part of children's education and development. But how do we develop tools to focus on the somatic 
dimension? How do children experience their bodies in movement? And how can they express their embodied experiences? With this article, I wish to dig deeper into these questions through presenting a multi-modal approach which I have developed for interviewing children about their embodied experiences. The multi-modal approach could also be applied as a pedagogic tool that would help cast light on the questions highlighted above regarding the teaching of movement and dance in schools. As such, the multi-modal interview approach is the focus of the article, but the development of the approach is attuned to discussions of relationships between body, movement and language, and somatic approaches in teaching.

In the research project titled Into the Movement: A Performative Phenomenological Field Study About Embodiment, Meaning and Creativity in Children's Learning Processes in Movement Education in Schools (Svendler Nielsen, 2008), I used video recordings and multimodal interviews to create a deeper understanding of eight year-old children's meaning-making processes in dance and physical education. An important methodological question in relation to children's meaning-making processes in movement is how to create knowledge about their embodied experiences. This is a question which I have explored by applying theories about the body's significance in learning and consciousness processes (Egan, 1997; Sheets-Johnstone, 1999), phenomenological theory and methods (Merleau-Ponty, 1962, 1968; Gendlin, 1983, 1997; van Manen, 1990), and somatic perspectives (Gendlin, 1997; Mindell, 1985).

\section{Theoretical Background}

The research presented here is based on an understanding of the body as both lived and expressed, and has its roots in Maurice Merleau-Ponty's (1962) phenomenological notion of embodiment (in French: “corporalité”), and in bodily approaches to investigating experiences and movement described by Eugene T. Gendlin (1997) and Arnold Mindell (1985, 1997). In this philosophical and psychological interpretative framework, embodiment is the "bodily being" understood as the physical body, the communicative expression, and the experienced "felt sense" of the body - all at once. The lived body is understood as "chiastic" (Merleau-Ponty, 1968): it is both seeing and seen, acting and acted upon, experiencing and experienced-by oneself and others. Metaphorically expressed, we are always entwined with one another and the world surrounding us. We influence and are influenced through our embodiment. Indeed, it is through our embodiment that we participate in the world at all.

\section{Creating Knowledge About Children's Embodied Experiences}

Now, I will ask you to join me in a second-grade class. The children are participants in my investigation of embodied experiences in dance and physical education. Their classroom is on the second floor, with big windows looking out on a green school yard filled with trees. Even though it is a rainy day in November, the room seems very light. It has been three months since I started following the class in their weekly physical education lessons and in their weekly dance lessons with a professional dance teacher who is running a project at the school. Today, the classroom teacher and I have agreed that I can spend a lesson 
giving an introduction to the individual interviews I will be carrying out during the coming months. Today we will do some introductory body awareness exercises all together that I will build on in the individual interviews. It is not easy to focus on embodied experiences or to verbalize them. I wonder how the children will react. Will they think that this is just too strange or will they enter the "game" with me?

The children usually sit grouped around round tables. We move the tables and chairs away from the centre, and I ask the children to find a spot on the floor. They all find a spot where they can stand and start looking interestedly in my direction. I start, "Shake your hands as much as you can while they are hanging in front of your bodies, then liiiift them up to the height of your shoulders, and let them stay there for a little while ..." The children start shaking their hands energetically, as much as they can, and slowly bring their arms up in tune with my voice. I continue, “Let's do it again. OK? Shake! All loose, all loose, all loose, all loose aaaaand let them move up to your shoulders and just staaand for a moment ..." I ask if they feel anything in their fingers.

"Yes!" some say.

"What do you feel?"

Viktor says, "It's tingling."

"It's tingling? Yes?"

Louise says, "It is really hard out in your arms when you have just been resting them.”

Signe adds, "I think it is because when you have just done like this then your blood is rushing around."

We try once more. It is as if an angel is passing through the room when they very gently lift their arms up. Thomas interrupts the stillness and says "It's tingling."

Sabine adds, "You get all hot."

And Signe says, "You also get all red out here on your nails and your fingertips."

I ask, "And why do you get red?" Many children raise their hands.

Signe herself answers, "Because the blood is running around out there."

Kristian says, "And then when you press your finger it gets white."

"Yes, it turns white because the blood disappears," I say and then continue, "We're doing these exercises so you can try out different ways to describe what you feel in your bodies." I ask the children to lie down on their backs. They all quickly lie down and squirm until they are comfortable. They lay spread out on the floor.

One child says, "You take up much more space when lying on the floor."

I answer, "Yes, because when you're standing it is really only your feet that take up space."

Signe says, "Now I feel that I am so heavy because my blood has rushed down.”

I say, "Yes! And now we will close our eyes and try and lie for a while and just breathe so that you can feel it all the way down in your bellies." The lesson goes 
on with more body awareness exercises. I also ask the children to draw their bodily sensation, first a sketch and afterwards they decide whether other colours could better serve to express their experience.

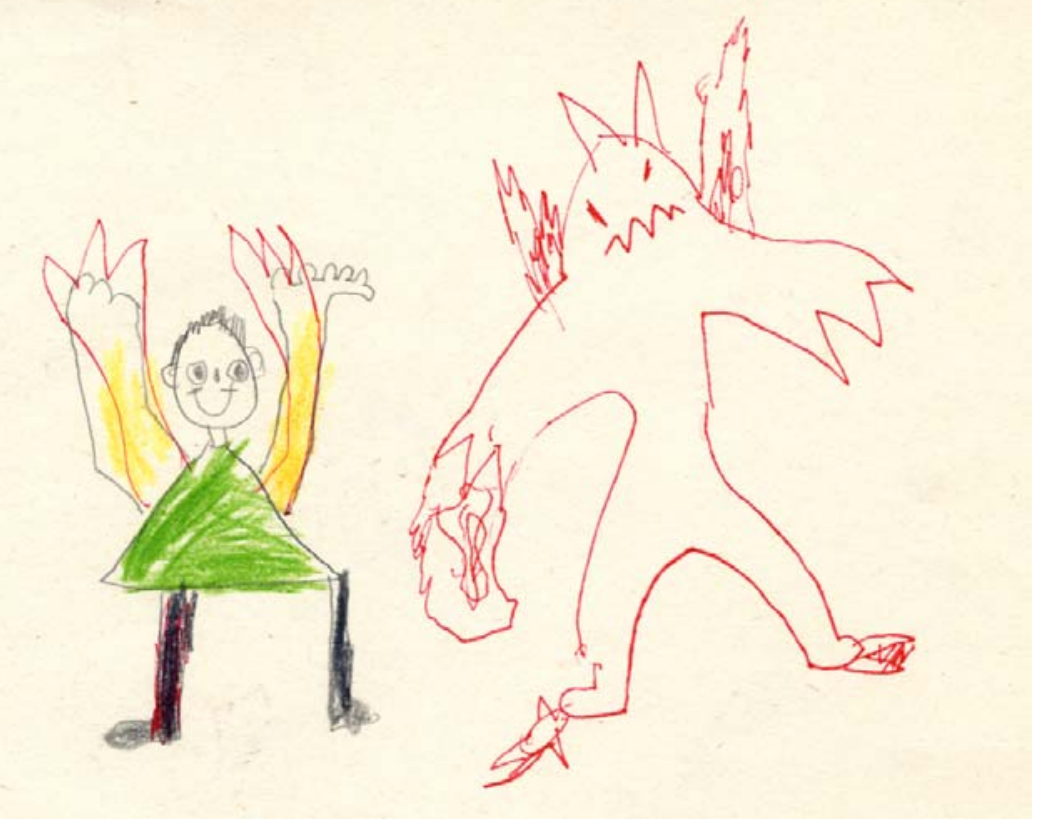

Figure 1: Tom’s drawing titled "Blood out in my fingers."

\section{Guide to Multi-Modal Interviews}

Neither children nor adults are often readily able to verbalize embodied experiences. But through multi-modal exercises and interviews, it is possible to practice feeling and expressing one's embodied experiences. Gendlin's “focusing technique” (1983) involves transforming experiences to verbal language so as to become more conscious of them, share them with others, and acquire tools to change or accept whatever it is that has occasioned the sensation- "the felt sense” (Gendlin, 1983). Some psychotherapists inspired by Gendlin also employ drawing as a method to investigate the felt sense (Lejissen, 1992; Rappaport, 1988; Stapert, 1997). As a part of the research presented here, I developed the multi-modal interview approach which puts the non-verbal in the forefront by giving children opportunities to focus on the felt sense and use their imagination as a way of opening up and expressing it through different modalities (Mindell, 1985). Inspired by Mindell's (1985) work on shifting channels in experiential modes, I have expanded Gendlin's focusing technique even further by providing the children with opportunities to express themselves in many modalities - through words and metaphors, colours, drawing, sound, music, and movement. 


\section{Choosing a "significant moment".}

The child chooses a significant moment, ${ }^{2}$ a movement or an experience. Either we begin talking about a drawing that the child has made beforehand showing a significant experience in dance or physical education, or I ask the child to choose a movement that he or she likes to do. I ask what the movement is, if the child would like to show it to me, and then we do the movement together.

\section{The "immediate felt sense" of the movement/ experience.}

When a drawing is the starting point, I begin by asking the child to tell me about the drawing. Then, I ask the child to find words that describe how it felt "in the body" to do the movement that has been drawn. In order to make the child focus on the felt sense of the moving body, I suggest that the child does the movement and tries to focus on how it feels to do it, and then we do it together. This lets me also experience how it feels to do the movement. That I involve myself bodily with the child also helps to intensify our communication in the situation, because the children involve themselves even more than when I just sit and watch them. While we move together I ask the child what it feels like and I explain what I feel. This leads to dialogue about our experiences. If the child finds it difficult to verbalize the experience, I give an example, "What feels good to me is that I feel that I am in a kind of rhythm. Do you also feel that?" Offering an example often works as a cue that makes the child enter the "game" and go on from there. Together we create some new insights into our movement experiences; the interviews become an embodied learning process_-both for the children and for me.

\section{"Clearing the space" and "the felt sense" again.}

I now tell the child that we are going to conduct a little experiment. I suggest that we close our eyes briefly and imagine how it feels to do the movement. I emphasize that closing their eyes is a choice, but not something that the child must do. Closing their eyes when they are alone with an adult who they do not know very well can, for some children, feel too intimidating (Stapert, 1997). However, all the children that I interviewed as part of this research closed their eyes without further ado and did not seem to feel uncomfortable. When we have focused on the experience for a little while, I ask if the child feels the sensation all over their body or in some specific body parts. And then I ask if she/he can find a word that describes the sensation. Some find this a very difficult task. If they do not say anything I suggest some ideas like "is it true to say that it feels, for example, bubbly or sharp?" Some children then find a word themselves, while others choose one of the words that I have mentioned. 


\section{"Channel shifting" and "attuning".}

Depending upon how easy or difficult it seems to be for the child to understand my questions, I try different ways to help the child express the embodied experiences, either in language or through other modes of expression. I suggest communicating in other modalities by asking if the sensation can be described by a colour or sound. If the child says "blue" in order to attune the experience, I ask if red could also be a possibility. If the child keeps to blue, I ask if it is a light or a dark blue, and what the difference between light and dark blue is. The children usually join "the game" and find it easy to relate the movement experience to a colour. For the interviews I bring a variety of musical instruments (e.g., a drum, a triangle, and a tambourine) which the children can use to communicate the embodied experience through sound. But I also mention that they are welcome to find other sounds and instruments. Some choose to make a sound that simulates the sound of the movement (if the movement is to jump like a ball the sound can be drumbeats that sound like a jumping ball). If the child chooses a drum, I ask, for example, if the tambourine is also a possibility, in order to help to nuance and "attune" which auditory image best expresses the experience.

\section{"Synthesizing" and "application".}

I try to find out if the child can distinguish between the embodied sensation and the image that he or she has of the form of the movement. I ask the child to make a new drawing, a quick drawing of what it looks like to do the movement. After that I ask if the child would like to draw the experience of moving like he or she has explained (for example, the experience of running). The goal is to create an understanding of the difference of the sensations we have while moving in certain moments-in contrast to how the movements look from the outside.

\section{"Closing" and "orientation ahead".}

It is very important that the children leave the interview with a sense of success. I try to make sure that they feel that they have understood what the exercise was about and that they have participated in a good way. With some children, the dialogue becomes so intense that we have to "rise to the surface" again together before I can finish the interview. I cannot just stop and say, "Well, goodbye and thanks for coming." I try to discern whether we are both ready to finish the conversation by introducing some ordinary subjects and giving the child space and time to see if he or she comes forth with other needs to talk about.

Children are individuals with different experiences and interests. With each child I, therefore, use the presented guide in a different way. In each situation, I estimate how it would be constructive to start the focusing exercises and how deep I can go with the child. Gendlin (1983, p. 67) has "clearing the space" as the first part of his focusing method, but with many children I feel it works better to start the exercise by doing the movement that they have chosen to tell about, and to make some opening efforts to verbalize the experiences before going deeper into the focusing process. 


\section{An Embodied Research Process}

Phenomenological research always begins “in the lifeworld” (van Manen, 1990, p. 7), and has as its aim to create deeper understandings of the meaning of experienced phenomena. The essence of a phenomenon can be "described through a study of the structure that governs the instances or particular manifestations of the essence of that phenomenon" (ibid., p. 10). Hermeneutic phenomenological research (van Manen, 1990) is basically characterized by a research process that takes place in the production of texts. But when "text" is understood in a broader sense (i.e., "action as text”), as it is the case in the writings of hermeneutic philosopher Paul Ricoeur (2002a, p.61), conceptualization can take place not only during the writing process, but also, for example, in the creation of visual narratives and film (e.g., Svendler Nielsen, 2008).

During the focusing exercises, I encourage the children to use various modes of expression to describe their embodied experiences. Through their choice of words, the children show how they understand my questions regarding their embodied sensations, how they relate to movement activities and make meaning while expressing their experiences. I have collected their direct statements from the interviews, sentences from log books, and words and drawings that they have made about their experiences, and transformed them into narratives.

As a researcher in the process of hermeneutic phenomenological analysis, I move between moments of closeness and moments of distance in relation to the phenomena and the children whose experiences and practices I am exploring (Todres, 2007, p. 58). The moments of closeness happen when I am involved in communicating the children's and my own experiences by bringing the essences of the experiences to a verbal form as first-person narratives. These narratives can help to get to the core of the phenomenon of embodied experience by making related special themes/lived meanings visible. The moments of distance happen when I seek to pull meanings forward from the texts through hermeneutic interpretations in which I constantly move between single sentences and the whole narrative in order to get to a deeper understanding of the meanings that are communicated about the phenomenon. A hermeneutic phenomenological approach (van Manen, 1990) highlights that the interpretation of a social situation is to treat the situation as a "text" and look for metaphors that appear in the text. In the analysis I therefore "feel into" what words, associations, and metaphors the children use to express themselves about their lived movement experiences and meanings.

The interpretation process takes place both during the interview, in the transcription of the recordings, and in the analysis of the material. According to the Finnish dance researcher Jaana Parviainen (2002), a dance teacher makes use of her or his own embodied experiences and kinaesthetic empathy to understand the participants' experiences, and to help learners in their learning process. Phenomenologically speaking, empathy is "an act of knowing within others" (Stein, 1917, as cited in Parviainen, 2002). Parviainen claims that we can make sense of another person's kinaesthetic experience through verbal communication, or through empathic understanding. Former dancer and phenomenologist Maxine Sheets-Johnstone (1999, p. 57) highlights that "we can distinguish kinetic bodily feelings such as smoothness and clumsiness, swiftness and slowness (...) we make bodily-felt distinctions.” To be able to conceptualize such nuances in movement requires sensitivity to differences in movement qualities. Moreover, in order to delve into and understand other people's movement experiences from their viewpoint we need embodied sensitivity (Parviainen, 2002, p. 148). This also applies to me as a researcher when I try to capture the children's embodied experiences. My own embodied experiences 
influence my investigation of experiences in the movement-education area. I seek to understand the children's experiences in an embodied way by watching and joining them in their movements. In the mimetic process (Ricoeur, 2002b, p.75-126), my visual and kinesthetic senses work together to give me an embodied experience like the one the child is trying to communicate. In all phases of the project I strive to understand what the children express, and listen with my whole body through kinesthetic empathy, but also with an openness to other forms of expression. In order to analyse the children's experiences, perspectives, and ways of moving and making meaning through and about movement, I must accept and welcome plurality in forms of expression and interpretation by paying attention to how and what the children say and do, and by making space for their direct choice of words (their "voices”).

\section{The Interview as a Touching Dialogue}

From a phenomenological perspective, the existential situation for both the child and me, as a researcher, is the living meeting that comprises an interview. Once in a while, subjects arise during the interviews that I could explore if the purpose were therapeutic, but because I am in an educational context, I consciously focus on the learning process. But it is a delicate balance. A dialogue can be so deep that both parties are touched. The same applies in teaching situations when themes of a more personal nature arise, and as a teacher one has to consider what to delve into and what it might be better to talk to parents or other professionals about. As educators, we want to start processes of learning, and in those processes we cannot help touching upon personal aspects. But as an educational researcher, it is not my task to explore personal problems; ethically I cannot reveal the more personal thoughts that children bring up in the atmosphere of trust that we have created. On a few occasions I became aware of something that an adult closer to the child should know about, and asked the class teacher about the child's history. She could not discuss personal issues either, but I got the impression that my experiences with the children were no surprise. It may sound as if I have heard some terrible stories, but that is not the case. The personal issues are primarily about relationships, discussions of the social hierarchies in the class, about development of more positive self-images, and about children who have got more friends. The positive stories that can arise from being involved in a new subject, in this case the dance lessons; having the opportunity of being deeply bodily engaged; and having time to talk about those experiences is also important knowledge to the adults closer to the children.

In the following section, an example of one child's voice gives insights into what she experiences when performing movements that have made a certain impression on her, and how she expresses her embodied experiences. 


\section{Andrea's Voice: Absorbedness in an Image}

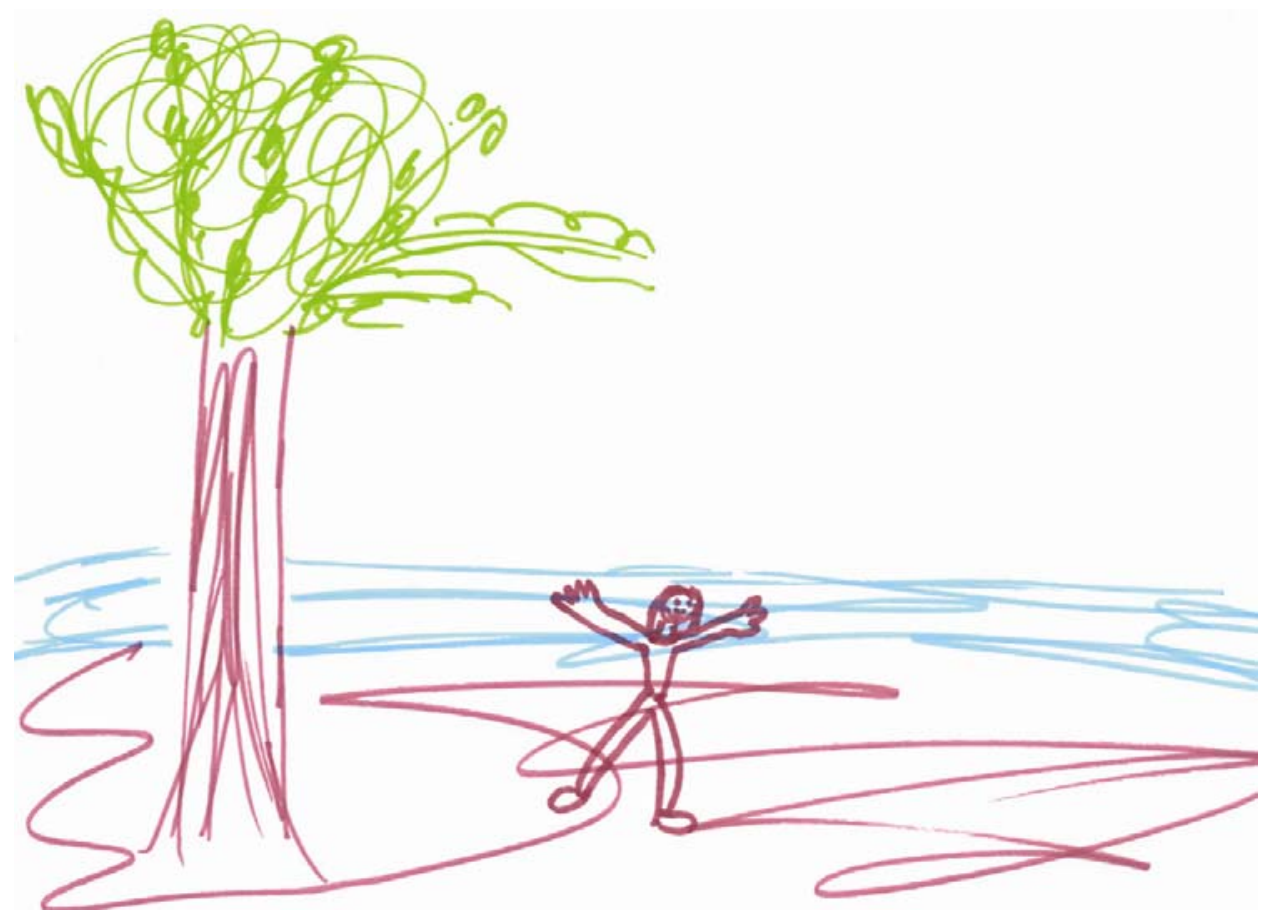

Figure 2: Andrea’s drawing titled "My dance as a fresh tree.”

“I am standing on 'Dancescenen' [the Dance Stage] acting a fresh tree. We are all tree forms or tree sculptures that are standing, planted in a half circle and move in different ways. When it is our group's turn to dance we go to the middle and the other ones come out and are trees again. There are many who are watching us. My fresh tree is stretching itself a lot and is standing only on one leg. It is a nice feeling and it is like a little breeze is coming, just like it is breezy outside and it is sort of swinging, it swings from side to side, and the breeze... I can feel it in my whole body, also in my legs. It is a little like being close to a beach where you can hear the breeze and the water is all blue.”

The significant movement experience that Andrea has chosen to talk about in the interview is from the children's performance on a professional dance stage which took place at the end of the dance project that I was following. Using Andrea's own words, I have developed this narrative in order to explicate the theme of "feeling absorbed in an image." This is the theme/lived meaning I find to be central through a "wholistic reading" (van Manen, 1990, p. 93) of the part of the interview when we talk about what a good movement experience is to her. Through a "selective reading" (ibid., p. 93), I see that Andrea's bodily being in the narrative both shows that in her absorbedness she is aware of her body as both expressive and as sensuous. She explains how she, in the on-stage performance, creates the expression of stretching like a fresh tree, but is also very 
sensuously aware of the movement experience. The sensuous dimension is expressed through her use of metaphors which show an identification with nature and the elements. The metaphors give an idea of what she experiences through her metamorphosis to a bodily tree. "The fresh tree" is standing well-planted in the soil (earth). She is close to the sea (water), and the air is breezy. Her body, which according to Merleau-Ponty (1968, p. 139) is the fifth element, is a tree that stretches. In the dance she is using her imagination and experiences her body and the tree as something which is alive and able to be transformed into one another. The experience of stretching is kinesthetic, as is the swinging sensation she has when the tree sways from side to side. In her images of nature, Andrea relates to visual images and they facilitate the auditory and kinesthetic modes; she both hears and feels how it is to be close to the sea and the breeze. The colours (i.e., purple, green, and blue) in which Andrea chooses to draw her experience of moving like a fresh tree and the sounds and metaphors that she connects to the movement experience contribute to communicating the dynamic qualities she experiences when moving.

In the analysis of the children's narratives, I elucidate how forms of movement merge with the sensing modes entered by the children via my guiding questions, and with the language they use to express themselves about the experience. The sensing, the movement, and the language that the children use to express their embodied experiences are dynamic and interwoven. The processes where the children connect to their experiences and express themselves about them take place in what Mindell (1985) calls “channels.” Mindell (1997, p. 20) distinguishes the following channels: the proprioceptive, the visual, the relational, the kinesthetic, the auditory, and the channel for "world phenomena." In my analysis of 25 children's narratives, channels of kinesthetic, visual, auditory, relational, and universal (world phenomena) character appear. But I also distinguish an emotional, a cultural, an existential, and a kinetic ${ }^{3}$ channel, or mode, of expression. I see the word "channel" as a metaphor for the phenomenological understanding that highlights connections between body, mind, and the surrounding world (Merleau-Ponty, 1962; Sheets-Johnstone, 1999).

The children each experience his or her own body in movement, but the experiences are closely linked to experiences of their surroundings, to other children who are part of the situation they choose to tell about for example, or, as in the case of a girl who chose to tell me about her experiences of running, to other people or situations in their lives. I primarily elicit kinesthetic expressions for the children's experiences and move to questions that open towards visual and auditory expressions. But once in a while the children themselves change mode of expression, through a phenomenon that Mindell (1985, p. 37) calls “switching channels.” It happens when, for example, one suddenly changes focus from bodily sensations to images. For some of the children when I elicit their kinesthetic experiences, a multidimensional bodily sensation starts; the kinesthetic opens towards the relational. As in the case of the girl who tells about her running experiences, kinesthetic awareness invites memories in the "relational channel” (Mindell, 1997) as she suddenly remembers how it is to run holding her dad's hand. 


\section{The Metaphor as an Embodied Tool of Understanding}

Through phenomenological analysis of the children's narratives I distinguish many ways that they relate to experiences in movement and express them. Some see the embodied experiences primarily in images, some express their bodily-felt sense as a kinesthetic metaphor, while others describe or explain in more rational terms. The words that the children know in advance are not sufficient to express their embodied experiences verbally. That is why they invent metaphors that can help them communicate their experiences. "Ordinary words convey only what we know already; it is from metaphor that we can best get hold of something fresh" (Aristotle in Egan, 1997, p. 55). According to Egan (ibid., p. 58), "metaphor is one of our cognitive grappling tools; it enables us to see the world in multiple perspectives and to engage with the world flexibly." He also emphasizes that "metaphor is much more profoundly a feature of sense-making than the largely ornamental and redundant poetic trope some have taken it to be” (ibid.). Moreover, Egan (ibid., p. 54) mentions that young children are especially good at creating metaphors, and use them to get a handle on something new. To invent a metaphor for an experience shows a bodilyfelt understanding and the ability to translate this understanding to words or other expressions. The metaphor mediates between body, experience and language. In the children's narratives it appears that the metaphors that they invent during the focusing exercises indeed also are bodily tools of becoming aware, and that the metaphors can contribute to understanding how they make meaning in the reflective processes about movement experiences.

\section{The Multi- Modal Approach as a Pedagogical Tool in Education}

With inspiration from Egan's theory of education (1997) and Sheets-Johnstone's (1999) phenomenology of movement, it can be argued that experiential and creative bodily activities can contribute to further development of a child's “somatic thinking” and ways of learning. But Egan and Sheets-Johnstone only briefly touch upon how it is possible to work with a somatic approach in practice. In this article I have described my efforts to create connections between different modes of expression ("channels") in order to elucidate the children's embodied experiences. The multi-modal approach makes it possible to reveal how the body can be used to channel different forms of expression, and thereby provide a multidimensional, subtle sense of embodied experience and meaning making. This approach has cast light on the ways that children can create connections to their embodied experiences and describe them in different "languages" and through the use of metaphors that they invent to suit the situation. The channels, or the ways of understanding and expressing embodied experiences, that I discern in the children's narratives probably also exist among other groups of children and young people. Their descriptions might be different and they might invent other metaphors, but presumably their ways of experiencing and expressing would lie within the same broad variations as suggested by Mindell (1997) and described in this article.

Although developed to explore children's embodied experiences in interview situations, the various ways of relating to body and movement that I have seen through the multi-modal 
approach could also be applied in dance and movement education in schools. Working with body awareness exercises and expressing experiences in various modes could also, in teaching situations, highlight an embodied perspective of learning in movement by expanding the children's consciousness in and about movement, emphasising the lived body, the experiences and the connections between the children and their surrounding world. As a teacher, knowing that children respond to sensuous modalities in different ways, one can use different channels to raise awareness, help children focus on embodied experiences, and becoming good at expressing themselves about them. Such work will help answer the following questions:

- How can "focusing" and "switching channels" be used educationally?

- Can such approaches help to develop the children's embodied consciousness and expressive repertoire?

- Can attention on creating metaphors to communicate embodied experiences make the children more aware of their experiences?

- Does expression of embodied experiences enhance deeper experiences and learning, and how can this be a way to develop the movement-education field?

Children are good at entering "a bodily universe"-in fact, they are there all the time. But among the subjects taught in the Danish public schools, for example, physical education is the only one that focuses on bodily activities. Moreover, in practice the experiential and expressive opportunities of physical education are rarely at the forefront. If an educational system is to take seriously the fact that the body is an extremely important resource for learning and development, then children must learn to be aware of their own and others' experiences and to communicate what they sense, see, and feel in a bodily-based language. They can thereby develop greater consciousness in and about movement. Sheets-Johnstone (1999) argues that movement is the basis for consciousness and cognition, but it is also the basis for sensing the body and other people, as emphasized by Merleau-Ponty $(1962,1968)$. As human beings, we are always influencing and influenced by one another through our embodiment (Merleau-Ponty, 1968). Understanding and taking this relational dynamic of the lived body as "chiastic" could contribute significantly to developing awareness of our own and other's ways of being bodies, to developing tools for sensing and working with our bodies in many different ways, and enhancing the relationships between body, movement, and language in the educational systems. An enhanced awareness rooted in the lived body could influence the ways children experience themselves and others and, therefore, also have a societal significance, as such awareness affects children's well-being, their relationships and quality of life. 


\section{Endnotes}

${ }^{1}$ Thomas Hanna defines "soma" as "the body experienced from within, where we experience mind/body integration." "Somatics" are practices that focus on the integration between body and mind (http://www.somaticsed.com/whatIs.html).

${ }^{2}$ Van Manen (1990, p.163) mentions that descriptions of "significant moments" are central when we want to understand human experience and lived meanings.

${ }^{3}$ The difference between the kinetic and the kineasthetic can with inspiration from SheetsJohnstone (1999) be explained as differences between the actual doing of the movement -"I run", "I turn" etc. (kinetic) and the sensation of doing the movement (kinaesthetic).

\section{References}

Egan, K. (1997). The educated mind. How cognitive tools shape our understanding. Chicago: The University of Chicago Press.

Gendlin, E.T. (1983). Fokusering - hør hvad din krop fortceller dig. København: Apostrof.

Gendlin, E.T. (1997). Experiencing and the creation of meaning. A philosophical and psychological approach to the subjective. Evanston: Northwestern University Press.

Lejissen, M. (1992). Experiential focusing through drawing. The Folio, Fall 1992. Retrieved from http://www.focusing.org/chfc/article_index.html [24-11-2003]

Merleau-Ponty, M. (1968/2000). The visible and the invisible. Evanston: Northwestern University Press.

Merleau-Ponty, M. (1962/2002). Phenomenology of perception. London: Routledge.

Mindell, A. (1985). Working with the dreaming body. London: Routledge \& Kegan Paul.

Mindell, A. (1997). Selvudvikling på egen hånd. København: Klitrose.

Parviainen, J. (2002). Kinaesthesia and empathy as a knowing act. In A.M Fiskvik \& E. Bakka (Eds.) Dance knowledge - Dansekunnskap (Pp. 147- 154). 6th NOFOD conference. Proceedings. Trondheim 10th -13th January 2002. Norges Teknisk-Naturvidenskabelige Universitet.

Rappaport, L. (1988). Focusing with art and creative movement: a method for stress management. In Reader from children's focusing corner. Retrieved from http://www.focusing.org/chfc/article_index.html [24-11-2003]. 
Ricoeur, P. (2002a). Tekstmodellen - meningsfuld handling betragtet som tekst. In M. Hermansen \& J. D. Rendtorff (Eds.), En hermeneutisk brobygger: Tekster af Paul Ricoeur (Pp. 49-74). Århus: Forlaget Klim.

Ricoeur, P. (2002b). Tid og fortælling. Den trefoldige mimesis. In M. Hermansen \& J. Dahl Rendtorff (Eds.), En hermeneutisk brobygger: Tekster af Paul Ricoeur (Pp. 75-126). Århus: Forlaget Klim.

Sheets-Johnstone, M. (1999). The primacy of movement. Amsterdam: John Benjamins Publishing Company.

Stapert, M. (1997). Children focusing. Guiding and teaching children to focus. In Reader from children's focusing corner. Retrived from: http://www.focusing.org/chfc/articles/en/stapert_f_children.htm [02-10-2004].

Svendler Nielsen, C. (2008). Ind i bevcegelsen - et performativt fcenomenologisk feltstudie om kropslighed, mening og kreativitet i børns lereprocesser i bevcegelsesundervisning i skolen. [Into the movement: a performative phenomenological field study about embodiment, meaning and creativity in children's learning processes in movement education in schools]. PhD Thesis. Copenhagen: Department of Exercise and Sport Sciences, University of Copenhagen.

Todres, L. (2007). Embodied enquiry: phenomenological touchstones for research, psychotherapy and spirituality. New York: Palgrave Macmillan.

Van Manen, M. (1990). Researching lived experience: human science for an action sensitive pedagogy. New York: State University of New York Press. 